\title{
CDISC SDTM Subject Status Response Terminology
}

National Cancer Institute

\section{Source}

National Cancer Institute. CDISC SDTM Subject Status Response Terminology. NCI

Thesaurus. Code C124304.

Terminology associated with the subject status response codelist of the Clinical Data

Interchange Standards Consortium (CDISC) Study Data T abulation Model (SDT M). 